\section{Apologies to Bianconi}

SIR - National science policy has been a primary focus of mine for many years. It is a subject to which I have dedicated considerable time and energy. The issue of overselling science is an issue in national science policy that deserves not only mine but others' time and energy. Over the past year, I have conducted a public debate with editors from Nature, The Scientist and Research/Penn State about overselling science regarding biomimesis and bio-derived materials.

However, as a part of that debate, I am afraid that a colleague of mine, $\mathrm{Dr}$ Patricia Bianconi, may have been unfairly caught in the middle, and to the extent that she feels her research has been a victim in this debate, I extend to her this apology, as I never intended her research itself to be the focus of the debate.

In the policy memorandum I privately circulated to various agencies and persons, I used the word "duplicating". The statement was: "this result -- duplicating work precipitating very small crystals of any one of a dozen phases including CdS in an inorganic gel . . ..". While I believe the work derives from the general experiments done by many on crystallization in gels, Bianconi's work had the special feature that she obtained an organized array of crystals of CdS in an organic host. In this respect her work did not duplicate earlier research and contains novel and unreported findings. The significance of this work will, as in all science, be determined over the course of time. I recognize that some well respected scientists find her results to be quite significant.

It was also imprecise for me to state that Bianconi had not "read or cited" the literature. I had no first-hand knowledge of whether she had or had not read the literature. It was not cited. In large part, the literature to which I had referred was that setting forth the replamine process, published in the 1970s. My criticism of a failure to cite this literature was not aimed at Bianconi's Nature article (349, $315-317 ; 1991$ - decisions of whether to cite articles should fairly be decided by authors and reviewers), but at the Research/Penn State article, which includes a lengthy text on the biological connections of Bianconi's work, without reference to the biomimetic work at Pennsylvania State University reported in more than 50 papers and 80 patents leading to prosthetic devices as well as

\section{Correction}

The following reference, containing articles amplifying the point made in the letter by Josephson et al. (Nature 358, 618; 1992), was omitted from the reference list appended to that letter: Frontier Perspectives, Vol. 3 , No. 1 (Center for

Frontier Sciences, Temple University, Philadelphia, 1992). $\square$ electroceramic composites, which have gone all the way to the marketplace.

My focus was on the use of "biomimetic" or other bio-related terms by her and others in conjunction with the research in question. I never stated nor meant to imply or infer that she was careless, or engaged in lazy practices or cheating of any kind. Similarly, I have never meant to imply, nor do I believe now, that she engaged in any form of scientific misconduct. Finally, I regret that the private memorandum I circulated to funding agencies and others contained the imprecise statements I have referenced above, and that some of these statements were published in the open literature.

Unfortunately this whole affair has taken on an untoward tone. There have been errors, omissions and exaggerations - perhaps on both sides. It is time to close this chapter for the good of the university.

\section{Rustum Roy}

102 Materials Research Laboratory,

Pennsylvania State University,

University Park, Pennsylvania 16802, USA

\section{Animal welfare}

SIR - It was, I believe, Professor Thomas Jukes who wrote "To every complex question there is a simple answer - and it's wrong". The recent correspondence on animal welfare demonstrates the truth of his aphorism. Everyone thinks they know what is meant by welfare, but it cannot be measured directly and is extremely hard to define. Ultimately the well-being of an animal is a function of sensory perception and must relate to its physical and mental state; this is governed by a broad range of external factors and in turn influences the animal's behaviour, physiology, growth and production. Although changes can be regarded as indicators of welfare they are, unfortunately, also influenced by a large number of environmental factors.

Egg production in the laying hen, which Jukes clearly regards as a primary indicator of welfare ${ }^{1}$, is a good example. It is sensitive to relatively minor changes in variables such as photoperiod, ambient temperature and dietary energy content, none of which has much impact on welfare. One can, therefore, equate changes in egg production to welfare only if all other influential factors have been controlled. It follows that it is not possible to compare the egg production of hens in battery cages with that in some other husbandry system and infer that differences between them tell one anything about the relative states of welfare of the hens in the two systems. Still less can one argue, as Jukes appears to be doing ${ }^{1,4}$, that if production reaches some target value which is commercially satisfactory, it demonstrates that welfare is also satisfactory.

However, if production is measured within an experiment where all the main factors are controlled, and the treatments at issue are systematically varied, then information is obtained from which valid conclusions can be drawn. Such experiments, reviewed by $\mathrm{Hughes}^{3}$, demonstrate that the egg output of caged hens declines progressively as the number of hens per cage is increased and also as the space per hen is reduced. These two effects are independent and additive. On the basis of this criterion, then, to optimize the welfare of battery hens they should be given as much space as possible, while the numbers of hens in each cage should be reduced to a minimum. This can be regarded as no more than a starting point. If, as much research suggests ${ }^{4}$, hens need a nest site, have feet ill-adapted to standing for long periods on sloping wire floors and benefit from access to substrate for foraging and scratching, then far more radical design changes to housing systems are required to safeguard welfare. But that is another question.

Barry 0. Hughes

AFRC IAPGR,

Edinburgh Research Station,

Roslin,

Midlothian, EH25 9PS, UK

1. Jukes, T. H. Nature 355, 582 (1992)

2. Jukes, T. H. Nature $\mathbf{3 5 8}, 186$ (1992)

3. Hughes, B. O in Economic Factors affecting Egg Production (eds Freeman, B. M. \& Boorman, K. N.) 271-298 (Br, in Poultry Science, Edinburgh, 1975).

4. Appleby, M. C. Hens Suffer in Battery Cages?: A Review of the Scientific Evidence (Athene Trust, Edinburgh, 1991)

\section{NASA on a tether}

SIR - As an amateur sailor, I can guess what happened in the NASA tether experiment (Nature 358, 526 \& 529; 1992). When the satellite was released from the Shuttle and the tether unwound, it went slack and a 'riding [overlapping] turn' developed. Any seaman who winds in or pays out cable on a rotating capstan knows from bitter experience that he must control the cable to avoid this condition.

When the gravitational potential difference between the two vehicles applied a tension to the cable, the riding turn locked the other turns on the cable drum.

No marks to NASA, which should have asked a crane driver for advice.

W. M. Colles

87 Beaufort Road,

Havant, Hants PO9 3 HT, UK

NATURE - VOL 359 - 8 OCTOBER 1992 